\title{
Suppression of $\gamma$-Oscillations in the Dorsolateral Prefrontal Cortex following Long Interval Cortical Inhibition: A TMS-EEG Study
}

\author{
Faranak Farzan', Mera S Barr', Willy Wong ${ }^{2}$, Robert Chen $^{3}$, Paul B Fitzgerald ${ }^{4}$ and Zafiris J Daskalakis*,' \\ 'Department of Psychiatry, Center for Addiction and Mental Health, Faculty of Medicine, University of Toronto, Toronto, ON, Canada; ${ }^{2}$ The \\ Institute of Biomaterials and Biomedical Engineering, University of Toronto, Toronto, ON, Canada; ${ }^{3}$ Division of Neurology, Toronto Western \\ Hospital, University of Toronto, Toronto, ON, Canada; ${ }^{4}$ Alfred Psychiatry Research Center, The Alfred and Monash University School of Psychology, \\ Psychiatry and Psychological Medicine, Commercial Road, Melbourne, VIC, Australia
}

\begin{abstract}
Gamma $(\gamma)$-oscillations $(30-50 \mathrm{~Hz})$ represent important electrophysiological measures, which are generated through the execution of higher order cognitive tasks (eg, working memory) in the dorsolateral prefrontal cortex (DLPFC). By contrast, cortical inhibition (Cl) refers to a neurophysiological process in which GABAergic inhibitory interneurons selectively suppress the activation of other neurons in the cortex. Recently, abnormalities in both $\mathrm{Cl}$ and $\gamma$-oscillations have been associated with various neuropsychiatric disorders including schizophrenia. Animal research suggests that suppression of $\gamma$-oscillations is, in part, mediated through GABAergic inhibitory neurotransmission. However, no such evidence has been demonstrated in human, largely because of technological limitations. Recently, we reported on novel methods permitting the recording of $\mathrm{Cl}$ from the DLPFC through transcranial magnetic stimulation (TMS) combined with electroencephalography (EEG). The aim of this study was to examine the effects of GABAergic inhibitory neurotransmission on $\gamma$-oscillations by combining TMS with EEG. Long interval cortical inhibition (LICl), a paired TMS paradigm, was used to index $G_{A B A}$ receptor mediated inhibitory neurotransmission in the motor cortex and DLPFC of healthy individuals. $\gamma$-Oscillations were significantly inhibited by $\mathrm{LICl}(38.1 \pm 26.5 \% ; p \leqslant 0.013)$ in the DLPFC but not in the motor cortex. These results provide neurophysiological evidence to demonstrate $\gamma$-oscillations are inhibited by $\mathrm{LICl}$ in the DLPFC but not in the motor cortex. Such specificity suggests that the modulation of $\gamma$-oscillations may represent an important neurophysiological process that may, in part, be responsible for optimal DLPFC functioning in healthy human subjects.

Neuropsychopharmacology (2009) 34, I543- I55 I; doi:I0. I038/npp.2008.2 I I; published online 26 November 2008
\end{abstract}

Keywords: TMS; EEG; GABA $;$; ; dorsolateral prefrontal cortex

\section{INTRODUCTION}

Cortical inhibition (CI) refers to a neurophysiological process in which cortical $\gamma$-aminobutyric acid (GABA) inhibitory interneurons selectively attenuate the activity of other neurons in the cortex. Previous studies have shown that CI can be studied through the application of paired pulse transcranial magnetic stimulation (TMS) over the motor cortex and measured through the attenuation of motor evoked potential (MEP) in the peripheral muscle as recorded through electromyography (EMG). Several studies (Valls-Sole et al, 1992; Sanger et al, 2001; Chen, 2004; Chu

*Correspondence: Dr ZJ Daskalakis, Department of Psychiatry, Center for Addiction and Mental Health, Faculty of Medicine, University of Toronto, 250 College Street, Toronto, ON, M5TIR8 Canada, Tel: + | 416535850 I, ext. 4319, Fax: + | 416979 6936, E-mail: Jeff_Daskalakis@camh.net

Received 23 July 2008; revised 26 September 2008; accepted 25 October 2008 et al, 2008; Florian et al, 2008) have examined CI in the motor cortex through a paired pulse TMS paradigm known as long interval cortical inhibition (LICI) in which application of a conditioning stimulus (CS) within an interval of 50-200 ms before a test stimulus (TS) suppresses the amplitude of the MEP following the TS by about $50 \%$ (Daskalakis et al, 2002) compared to a single TS alone. Several lines of evidence suggest that LICI reflects $G_{A B A}$ receptor mediated inhibitory neurotransmission. For example, the fact that LICI inhibits another inhibitory paradigm, short interval cortical inhibition (Sanger et al, 2001), which relates to $\mathrm{GABA}_{\mathrm{A}}$ receptor mediated inhibitory neurotransmission (Ziemann et al, 1996b), is consistent with the suggestion that presynaptic $G_{A B A}$ may inhibit the release of GABA with a concomitant decrease in $\mathrm{GABA}_{\mathrm{A}}$ receptor mediated inhibition (Werhahn et al, 1999). Also, LICI is evoked with a high intensity CS that produces longer periods of CI (Valls-Sole et al, 1992), which is consistent with the finding that $\mathrm{GABA}_{\mathrm{B}}$ receptor mediated responses 
have higher activation thresholds and their inhibitory influence is longer lasting (Deisz, 1999; Sanger et al, 2001). Further, the administration of $\mathrm{GABA}_{B}$ receptor agonist baclofen was found to potentiate LICI (McDonnell et al, 2006).

During the past few decades, numerous electroencephalography (EEG) studies have examined the functional roles of cortical oscillations in various brain regions. For example, it has been demonstrated that oscillations in the $\theta(4-7 \mathrm{~Hz}), \alpha(8-12 \mathrm{~Hz})$, and $\beta(12.5-28 \mathrm{~Hz})$ band frequency are more closely associated with movement-related phenomenon. Short lasting $\beta$-oscillations have been observed following voluntary hand movement (Pfurtscheller et al, 1997; Lalo et al, 2007) whereas lower frequency oscillations such as, $\delta(1-3 \mathrm{~Hz})$ have been linked with sleep. By contrast, cortical oscillations in the $\gamma(30-50 \mathrm{~Hz})$ band frequency recorded from the dorsolateral prefrontal cortex (DLPFC) and the hippocampus represent important electrophysiological processes, which have been associated with higher order cognitive tasks including working memory (TallonBaudry and Bertrand, 1999; Howard et al, 2003; Kaiser and Lutzenberger, 2003; Missonnier et al, 2003). For example, increases in working memory loads have been associated with increases in the power of induced $\gamma$-oscillations in the DLPFC of healthy human subjects (Howard et al, 2003) and abnormalities of $\gamma$-oscillations have been associated with the working memory deficits in patients with schizophrenia (Cho et al, 2006).

To this date, several in vivo and in vitro studies have demonstrated that the activation of $\mathrm{GABA}_{\mathrm{B}}$ receptors suppresses the stimulus-induced or the spontaneous activity of $\gamma$-oscillations. For example, animal studies have shown that administration of $\mathrm{GABA}_{\mathrm{B}}$ receptor agonists such as baclofen eliminates $\gamma$-oscillations in rat hippocampal slices (Brown et al, 2007), whereas the blockade of $\mathrm{GABA}_{\mathrm{B}}$ receptors has been shown to enhance the $\gamma$-oscillations in the hippocampus of behaving rats (Leung and Shen, 2007). Consistent with these studies, the stimulus-induced attenuation of $\gamma$-oscillations was enhanced following the injection of tiagabine (Brown et al, 2007).

Recently, we have reported on novel techniques, which combine TMS with EEG to measure LICI in both the DLPFC and motor cortex (Daskalakis et al, 2008). Through these methods, we further endeavored to compare the modulatory influence of LICI on cortical oscillations across the five frequency bands (ie, $\delta(1-3 \mathrm{~Hz}), \theta(4-7 \mathrm{~Hz}), \alpha(8-12 \mathrm{~Hz})$, $\beta(12.5-28 \mathrm{~Hz}), \gamma(30-50 \mathrm{~Hz}))$ in the motor cortex and the DLPFC in healthy subjects. It was hypothesized that LICI modulation of $\gamma$-oscillations would be more pronounced in the DLPFC compared to the motor cortex given the functional importance of this frequency band in higher order cognitive processes.

\section{METHODS}

\section{Participants}

We studied 14 healthy, right-handed volunteers (mean age $=35.8$ years, $\mathrm{SD}=8.1$ years, range $=23-47$ years; seven men and seven women), the first nine of which had previously participated in our earlier published study (Daskalakis et al, 2008). Handedness was confirmed using the Oldfield Handedness Inventory (Oldfield, 1971). All subjects gave their written informed consent and the protocol was approved by the Center for Addiction and Mental Health in accordance with the Declaration of Helsinki Principles. Exclusion criteria included a selfreported comorbid medical illness or a history of drug or alcohol abuse. Moreover, psychopathology was ruled out through the personality assessment screener (PAS; Psychological Assessment Resources Inc.). The PAS is a selfadministered, objective inventory of adult personality and psychopathology (eg, personality depression, somatic disorders, anxiety, anxiety-related disorders, and schizophrenia), comprising nonoverlapping clinical, treatment, interpersonal, and validity scales. Specifically, the PAS measures manifestation of clinical syndromes, providing information to assist diagnosis, treatment, and screening for all psychopathology corresponding DSM-IV categories (Morey, 1991, 1996).

\section{Experiment Design}

TMS was administered over the left motor cortex and DLPFC of all subjects. Inhibition was measured through LICI and indexed through EMG and EEG. LICI involves pairing of a suprathreshold CS followed by a suprathreshold TS at long interstimulus intervals (ISIs; eg, $100 \mathrm{~ms}$ ), which inhibits the MEP produced by the TS (Valls-Sole et al, 1992). LICI is reportedly optimal at $100 \mathrm{~ms}$ ISI (Sanger et al, 2001), and as such, in this experiment we evaluated LICI at this interval (ie, $\operatorname{LICI}_{100}$ ). Both the $\mathrm{CS}$ and TS were suprathreshold and adjusted to produce a mean peak-topeak MEP amplitude of $1 \mathrm{mV}$. One hundred TMS stimuli were delivered per condition (paired CS-TS and TS alone) every $5 \mathrm{~s}$, an interval conventionally used in most TMS studies evaluating CI that has not been shown to result in long-term depression of stimulus amplitude with repeated stimulation (Kujirai et al, 1993; Ziemann et al, 1996a; Nakamura et al, 1997; Sanger et al, 2001). Moreover, to control for the effect of TMS click-induced auditory activation on the cortical evoked potentials, single and paired pulse sham stimulation was administered in a subset of 10 subjects (mean age $=37.1$ years, $\mathrm{SD}=7.1$ years, range $=26-47$ years; seven men and three women) at the same intensity as used for active stimulation but with the coil angled at $90^{\circ}$ from the scalp resting on one wing of the coil. All conditions (paired CS-TS/TS alone, motor cortex/ DLPFC, active/sham) were randomly counterbalanced between subjects to avoid order effects. During the experiment subjects were sitting in a comfortable armchair with their eyes open, their elbow flexed, and their hands rested on a pillow placed on their laps.

\section{Data Recording}

TMS. Monophasic TMS pulses were administered to the left motor cortex and DLPFC using a $7 \mathrm{~cm}$ figure-of-eight coil, and two Magstim 200 stimulators (Magstim Company Ltd, UK) connected by a Bistim module. We examined LICI in the motor cortex through simultaneous recording of both EMG and EEG, and in the DLPFC through EEG only. In both regions, the optimal position was marked on the EEG cap with a felt pen to ensure identical placement of the coil 
throughout the experiment, and the handle of the coil pointed backward, perpendicularly to the presumed direction of the central sulcus, approximately $45^{\circ}$ to the midsagittal line. The intensity of TMS pulses was determined at the beginning of each experiment and it was set such that it elicited an average MEP of $1 \mathrm{mV}$ peak-to-peak amplitude upon delivery of 20 pulses over the motor cortex, and this corresponded to $62.8 \pm 11.8 \%$ of stimulator output in 14 subjects who participated in active stimulation and to $62.4 \pm 12.2 \%$ in 10 subjects who participated in the sham experiment.

Localization of motor cortex. In stimulating the motor cortex, the TMS coil was placed at the optimal position for eliciting MEPs from the right abductor pollicis brevis (APB) muscle, which typically corresponded to a region between FC3 and C3 electrodes on the 10-20 EEG system (Herwig et al, 2003).

Localization of DLPFC. Localization of DLPFC was achieved through neuronavigation techniques using the MRIcro/reg software and a T1-weight MRI scan obtained for each subject with seven fiducial markers in place and MINIBIRD system, which has a resolution of $0.5 \mathrm{~mm}$ in position and $0.1^{\circ}$ in orientation, with a static accuracy of $1.8 \mathrm{~mm}$ root mean square (RMS) in position and $0.5^{\circ} \mathrm{RMS}$ in orientation (Ascension Technologies, USA). Stimulation was directed at the junction of the middle and anterior one-third of the middle frontal gyrus (Talairach coordinates $(x, y, z)=(-50,30,36))$ corresponding with posterior regions of Brodmann area (BA) 9, which overlap with the superior section of BA 46. This site was chosen based on a recent meta-analysis of functional imaging studies of working memory and the DLPFC (Glahn et al, 2005; Mendrek et al, 2005; Tan et al, 2005).

EMG recording. EMG was captured by placing two disposable disc electrodes over the right APB in a tendonbelly arrangement and MEPs were filtered (band pass $2 \mathrm{~Hz}$ to $5 \mathrm{kHz}$ ), digitized at $5 \mathrm{kHz}$ (Micro 1401; Cambridge Electronics Design, Cambridge, UK), and collected through commercially available software Signal (Cambridge Electronics Design) according to our previously published methods (Daskalakis et al, 2002).

EEG recording. To evaluate TMS-induced cortical evoked potentials, EEG was recorded concurrently with the EMG. EEG was acquired through a 64-channel Synamps2 EEG system using a 64-channel EEG cap, and four electrodes were placed on the outer side of each eye, and above and below the left eye to monitor the eye movement artifact. All electrodes were referenced to an electrode placed posterior to the $\mathrm{Cz}$ electrode. EEG signals were recorded with filters at DC to $100 \mathrm{~Hz}$ at $20 \mathrm{kHz}$ sampling rate, which was shown to avoid saturation of amplifiers and minimize the TMS-related artifact (Daskalakis et al, 2008).

\section{Data Analysis}

In the motor cortex, $\mathrm{LICI}_{100}$ was evaluated through both EEG and EMG, which were referred to as EEG and EMG measure of $\mathrm{LICI}_{100}$. In the DLPFC, $\mathrm{LICI}_{100}$ was evaluated through EEG only.

EMG measure of inhibition. For each subject, the EMG measure of $\mathrm{LICI}_{100}$ was indexed by comparing the area under the rectified curve of average MEP following the single pulse of TMS (unconditioned) with the area under curve following the paired pulses of TMS (conditioned) and the inhibition was obtained as follow:

$$
\left[1-\frac{\text { Area under rectified curve (conditioned) }}{\text { Area under rectified curve (unconditioned) }}\right] \times 100
$$

EEG measure of inhibition. The EEG recordings were first processed offline by commercially available software, Neuroscan (Compumedics, USA). The EEG data were down sampled to $1 \mathrm{kHz}$ sampling frequency, and segmented with respect to the TMS TS such that each epoch included $1000 \mathrm{~ms}$ prestimulus baseline and a $1000 \mathrm{~ms}$ poststimulus activity. Epochs were baseline corrected with respect to the TMS-free prestimulus interval (1000-110 ms before the TS). The baseline corrected post-TS intervals $(25-1000 \mathrm{~ms})$, which were not contaminated by TMS artifact were extracted and digitally filtered by using a zero-phase shift $1-100 \mathrm{~Hz}$ band pass filter ( $48 \mathrm{~dB} / \mathrm{oct})$. At this stage, epochs were manually reviewed and trials $(9.2 \pm 1.9 \%$ of trials in each condition) contaminated with muscle activity, movement or TMS artifact were excluded from further analysis. Finally, the average signals at each recording site were computed from the movement-free epochs (approximately 80 trials per subject) and were fed into an automated eyeblink correction algorithm (Croft $e t$ al, 2005). The eye-blink corrected average EEG waveforms were then imported into MATLAB (The MathWorks Inc., Natick, MA, USA), and further analyses were carried out by means of EEGLAB toolbox (Delorme and Makeig, 2004). To quantify the EEG measure of $\mathrm{LICI}_{100}$ in all five frequency bands, for each subject, the average TMS evoked cortical potentials following single and paired pulses of TMS were decomposed into the $\delta(1-3.5 \mathrm{~Hz}), \theta(4-7 \mathrm{~Hz}), \alpha(8-12 \mathrm{~Hz}), \beta(12.5-28 \mathrm{~Hz})$, and $\gamma(30-50 \mathrm{~Hz})$ frequency components by means of a Hamming-based zero-phase shift finite impulse response filter, and for each frequency band inhibition was obtained through equation (1) (ie, area under rectified curve for averaged EEG recordings between 50 and $150 \mathrm{~ms}$ post-TS). The onset (ie, $50 \mathrm{~ms}$ poststimulus) was chosen as it represents the earliest artifact free data that can be recorded poststimulus and the offset (ie, $150 \mathrm{~ms}$ poststimulus) was chosen according to previously published studies (Sanger et al, 2001; Daskalakis et al, 2008). We referred to these measures as $\mathrm{CI}_{\delta}, \mathrm{CI}_{\theta}, \mathrm{CI}_{\alpha}, \mathrm{CI}_{\beta}$, and $\mathrm{CI}_{\gamma}$ to represent the extent of inhibition in each frequency band. Furthermore, to obtain the total amount of EEG inhibition, for each subject the TMS evoked cortical potentials following the single and paired pulse of TMS were band pass filtered $(1-50 \mathrm{~Hz})$ and $\mathrm{CI}_{\text {total }}$ was calculated through equation (1). Finally, to evaluate LICI directly from the motor cortex, C3 electrode was used as it has been shown to be the electrode that best represents evoked activity in the hand area of 
motor cortex and is closest to the optimal site of APB activation through TMS (Cui et al, 1999). To capture LICI in the DLPFC, the recording electrode of interest was AF3, which optimally represents the overlap of BAs 9 and 46 of the DLPFC (Herwig et al, 2003).

Statistical analysis. We used repeated measure analysis of variance (ANOVA) and two-tailed paired $t$-test to perform the statistical analysis. The group values were reported as mean $\pm S D$, and $p$-values less than 0.05 were considered significant. All statistical analyses were performed using MATLAB (The MathWorks Inc.) and SPSS 15.0 (SPSS Inc., Chicago, IL, USA).

\section{RESULTS}

\section{Motor Cortex}

Consistent with our previous study (Daskalakis et al, 2008), there was a significant suppression $(77.47 \pm 18.67 \%)$ in the mean area under rectified EMG curve through LICI $_{100}$ as compared to TS alone $(p \leqslant 0.0001)$. The mean area under rectified EEG curve (recorded from the C3 electrode), was also significantly suppressed through $\mathrm{LICI}_{100}$ as compared to TS alone $\left(\mathrm{CI}_{\text {total }}=41.86 \pm 28.74 \%\right.$; $p \leqslant 0.004)$, however, only the $\delta-\left(\mathrm{CI}_{\delta}=43.87 \pm 35.71 \%\right.$; $p \leqslant 0.015), \quad \theta-\quad\left(\mathrm{CI}_{\theta}=49.20 \% \pm 34.85 \% ; \quad p \leqslant 0.003\right), \quad$ and $\alpha-\left(\mathrm{CI}_{\alpha}=28.57 \pm 38.83 \% ; p \leqslant 0.055\right)$ oscillations were significantly suppressed. By contrast, $\beta-\left(\mathrm{CI}_{\beta}=10.93 \% \pm 45.34 \%\right.$; $p \geqslant 0.239) \quad$ and $\quad \gamma$-oscillations $\quad\left(\mathrm{CI}_{\gamma}=-7.54 \pm 50.17 \%\right.$; $p \geqslant 0.612$ ) were not significantly suppressed through LICI $_{100}$ (Figures 1 and 3).

\section{Dorsolateral Prefrontal Cortex}

There was a significant suppression in the area under the mean rectified $\mathrm{EEG}$ curve (recorded from the $\mathrm{AF} 3$ electrode) through $\mathrm{LICI}_{100}$ as compared to TS alone $\left(\mathrm{CI}_{\text {total }}=35.06 \pm 24.53 \%\right.$; $p \leqslant 0.001)$. However, unlike the motor cortex, all EEG rhythms were significantly suppressed $\left(\mathrm{CI}_{\delta}=29.86 \% \pm\right.$ $29.28 \% ; p \leqslant 0.002), \quad\left(\mathrm{CI}_{\theta}=30.59 \pm 30.33 \% ; p \leqslant 0.001\right), \quad\left(\mathrm{CI}_{\alpha}=\right.$ $31.72 \pm 32.14 \% ; \quad p \leqslant 0.002), \quad\left(\mathrm{CI}_{\beta}=37.13 \pm 24.12 \% ; p \leqslant 0.001\right)$, and $\left(\mathrm{CI}_{\gamma}=38.07 \pm 26.52 \%\right.$; $p \leqslant 0.002$; Figures 1 and 3$)$. Finally, out of 14 healthy participants, 11 subjects showed inhibition of $\gamma$-oscillations in the DLPFC. To distinguish responders from nonresponders, we performed linear regression analysis and found no relationship between $\mathrm{CI}_{\gamma}$ and individual neurophysiological parameters including the resting motor threshold $(p \geqslant 0.69)$, stimulation intensity $(p \geqslant 0.20)$ or demographic factors including age $(p \geqslant 0.47)$, sex $(p \geqslant 0.62)$, and years of education $(\geqslant 0.93)$.

\section{Comparison between the Motor Cortex and DLPFC}

Repeated measures ANOVA revealed a significant location (ie, motor cortex and DLPFC) by suppression across cortical oscillations (ie, $\mathrm{CI}_{\delta}, \mathrm{CI}_{\theta}, \mathrm{CI}_{\alpha}, \mathrm{CI}_{\beta}$, and $\mathrm{CI}_{\gamma}$ ) interaction $(\mathrm{F}=5.41, \mathrm{df}=4,22, p \leqslant 0.003)$. That is, there was a more pronounced suppression of higher frequency bands compared to lower frequency bands in the DLPFC compared to the motor cortex. Post hoc comparisons showed significantly greater suppression for $\mathrm{CI}_{\gamma}$
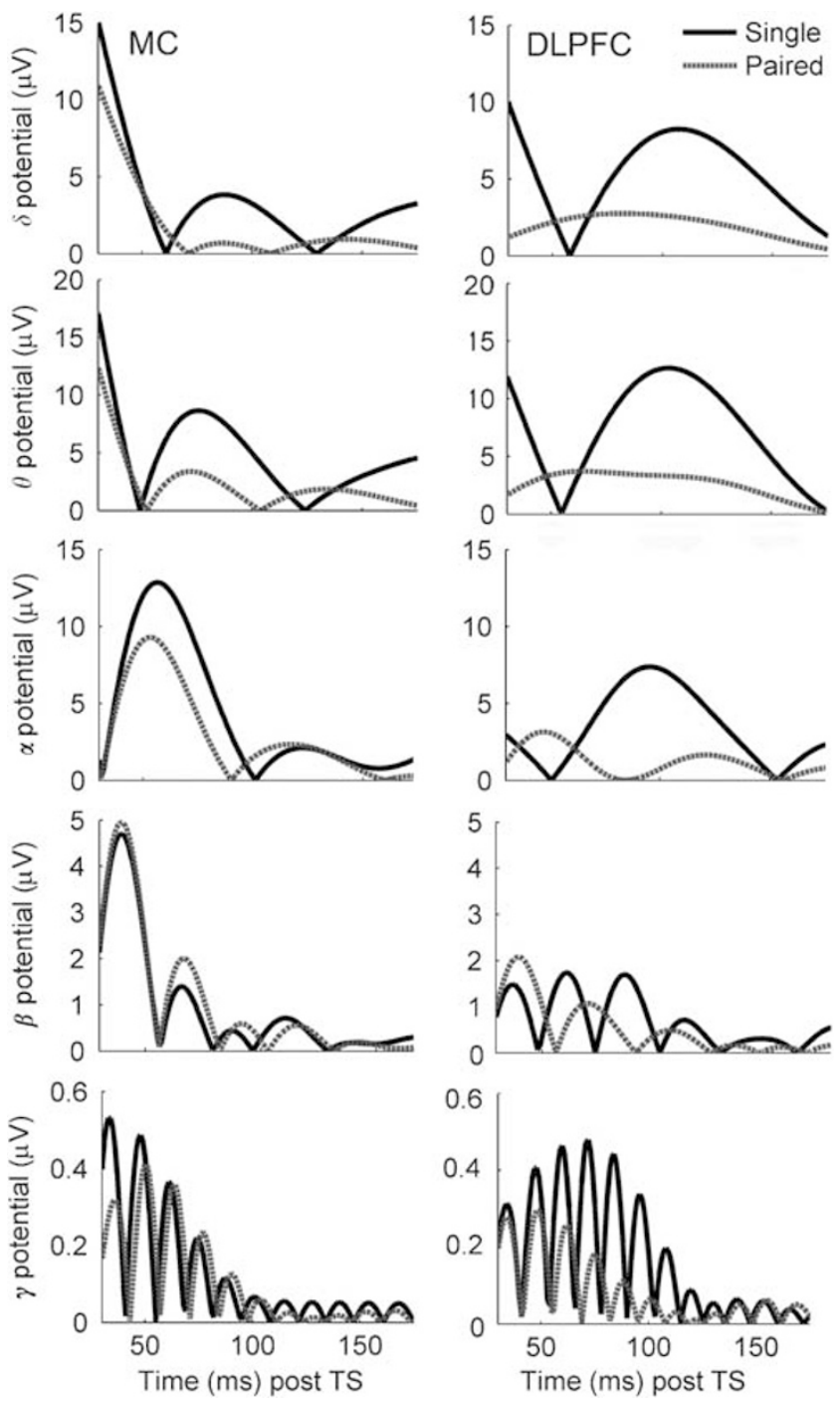

Figure I TMS evoked cortical oscillations following the application of $\mathrm{LICl}$ to the DLPFC and motor cortex. The waveforms represents mean rectified cortical oscillations in $\delta(1-3.5 \mathrm{~Hz}), \theta(4-7 \mathrm{~Hz}), \alpha(8-12 \mathrm{~Hz})$, $\beta(12.5-28 \mathrm{~Hz})$, and $\gamma(30-50 \mathrm{~Hz})$ frequency bands, from top to bottom, respectively, following the delivery of single (solid waveforms) and paired pulse (dash waveforms) of TMS to the left motor cortex (left panel) and the left DLPFC (right panel) and across all 14 subjects. In all figures, $x$-axis represent the time after the delivery of TS. In DLPFC, the $y$-axis represent the EEG potential recorded from the AF3 electrode, which optimally represents the overlap of BAs 9 and 46 of the DLPFC. In motor cortex, the $y$-axis represent the EEG potential recorded from the $C 3$ electrode, which was closest to the optimal site of APB activation through TMS.

$(p \leqslant 0.007)$ in the DLPFC than the motor cortex. $\mathrm{CI}_{\beta}$ showed a trend for greater suppression in the DLPFC $(p \leqslant 0.076)$. $\mathrm{CI}_{\delta}(p \geqslant 0.187), \mathrm{CI}_{\theta}(p \geqslant 0.144)$, and $\mathrm{CI}_{\alpha}(p \geqslant 0.810)$ were not significantly different between these cortical regions (Figures 2 and 3 ). Finally, we found no significant main effects of frequency $(\mathrm{F}=2.05, \mathrm{df}=4, p \geqslant 0.123)$ or location $(\mathrm{F}=0.616, \mathrm{df}=1, p \geqslant 0.440)$.

\section{Effect of TMS Click-Induced Auditory Activation}

To rule out the possibility that suppression of cortical evoked activity measured through LICI $_{100}$ could be because of the suppression of auditory evoked potentials (eg, N100 

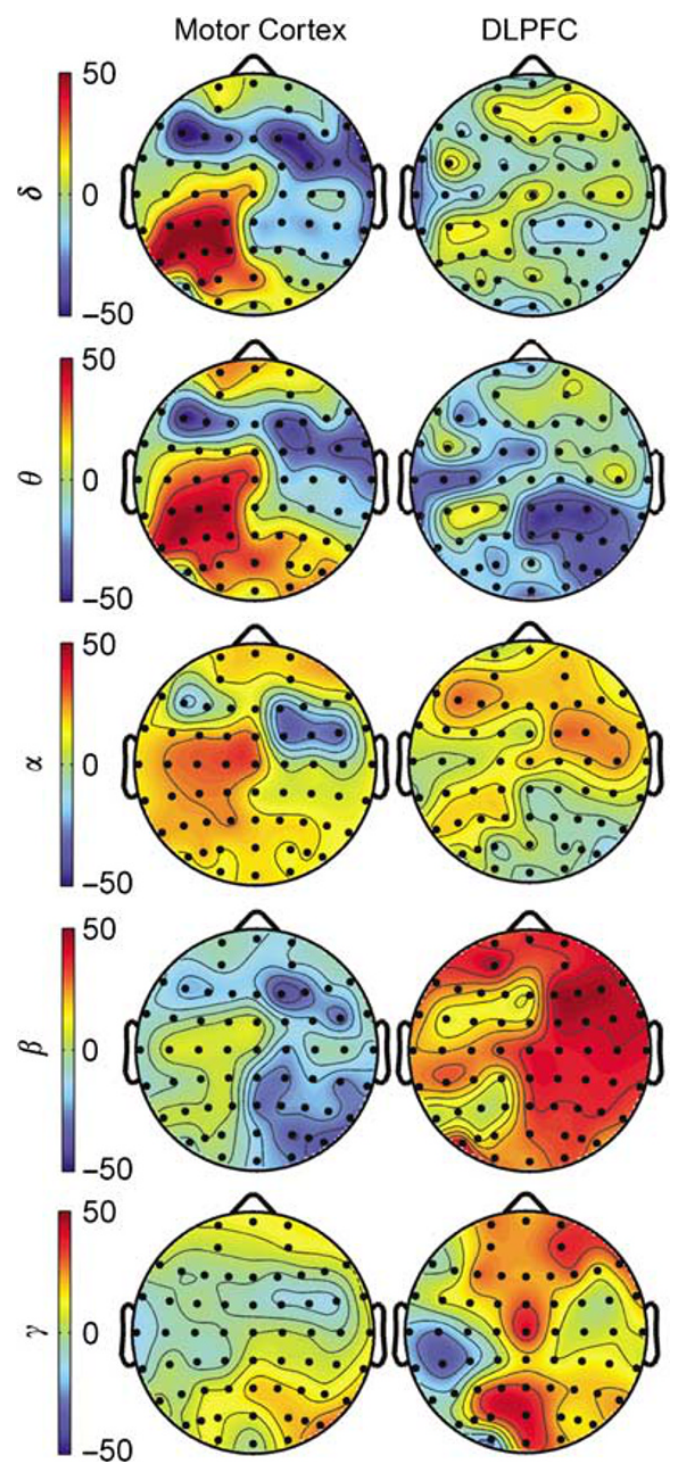

Figure 2 Topographic illustration of modulation of cortical oscillations in response to application of $\mathrm{LICl}$ to the DLPFC and motor cortex. Each topographic plot illustrates the average suppression of cortical evoked activity in response to application of LICl paradigm to the left motor cortex (left panel) and left DLPFC (right panel) across all I4 subjects. Inhibition is obtained by equation (I) (see Methods section), and hot colors represent the area of maximum inhibition. These plots suggest that, application of $\mathrm{LICl}$ to the motor cortex results in attenuation of $\delta$-, $\theta$-, and $\alpha$-oscillation, whereas in the DLPFC, $\beta$-, and $\gamma$-oscillations are inhibited the most. Topographic head plots were obtained by EEGLAB toolbox (Delorme and Makeig, 2004).

suppression following presentation of paired auditory clicks separated by $100 \mathrm{~ms}$ ), sham LICI $_{100}$ was applied for both the motor cortex and DLFPC. In this way, sham stimulation preserves the auditory stimulation produced by TMS clicks, without eliciting direct brain stimulation (Figures 4 and 5). To control for the effects of TMS-induced auditory activation, for subjects who had received both active and sham stimulation $(n=10)$, the cortical evoked potential following single and paired pulses of TMS in sham stimulation was subtracted from the TMS evoked cortical evoked potential in the active stimulation of both the motor cortex and the DLPFC (Daskalakis et al, 2008). In the motor cortex, suppression of cortical evoked potential did not change after controlling for the auditory evoked responses (active: $\mathrm{CI}_{\text {total }}=37.34 \pm 31.32 \%$; active-sham: $\left.\mathrm{CI}_{\text {total }}=34.62 \pm 35.80 \% ; \quad p \geqslant 0.40\right)$, and the suppression of TMS evoked cortical activity remained significant $(p \leqslant 0.020)$. Similarly, in the DLPFC, the suppression of $\mathrm{LICI}_{100}$ did not change following this subtraction (active: $\mathrm{CI}_{\text {total }}=34.32 \pm 27.62 \%$; $\quad$ active-sham: $\quad \mathrm{CI}_{\text {total }}=35.02 \pm$ $25.01 \% ; p \geqslant 0.88)$, and remained significant $(p \leqslant 0.004)$.

\section{DISCUSSION}

We investigated the effects of $G_{A B A}$ potentiation, evoked through $\mathrm{LICI}_{100}$, on the spectral characteristic of cortical oscillations in the motor cortex and DLPFC. Administration of $\mathrm{LICI}_{100}$ over the DLPFC suppressed the activity of all cortical oscillations as compared to TS alone with the maximum inhibition observed on $\gamma$-oscillations. By contrast, $\mathrm{LICI}_{100}$ applied over the motor cortex resulted in attenuation of low frequency components of EEG $(1-12 \mathrm{~Hz})$ with no inhibition in $\gamma$-oscillations.

Several animal studies and computer simulations have implicated GABAergic inhibitory neurotransmission in both the generation and modulation of $\gamma$-oscillations in the cortex (Bragin et al, 1995; Whittington et al, 1995; Jefferys et al, 1996; Traub et al, 1996; Wang and Buzsaki, 1996; Traub et al, 1997; Traub et al, 1998; Scanziani, 2000; Whittington et al, 2000; Bracci et al, 2001; Mann et al, 2005; Marrosu et al, 2006; Bartos et al, 2007; Brown et al, 2007; Mann and Paulsen, 2007; Trevino et al, 2007). These studies suggest that the $\mathrm{GABA}_{\mathrm{A}}$ receptor mediated inhibitory postsynaptic potentials (IPSPs) contribute to generation of $\gamma$-oscillations (Whittington et al, 1995; Wang and Buzsaki, 1996; Bartos et al, 2007). For example, Whittington et al (1995) showed that activation of glutametergic receptors in slices of rat hippocampus and neocortex, resulted in synchronous $40 \mathrm{~Hz}$ oscillations in networks of inhibitory neurons connected by synapses containing $\mathrm{GABA}_{\mathrm{A}}$ receptors, and $\gamma$-oscillations were completely blocked following the application of the $\mathrm{GABA}_{\mathrm{A}}$ antagonists, bicuculline. Furthermore, through computer simulation, Wang and Buzsaki (1996) demonstrated that the synaptic time constant of $\mathrm{GABA}_{\mathrm{A}}$ receptors make them suitable candidates for providing the synchronicity observed within the $\gamma$-band. By contrast, it has been suggested that $G_{A B A}$ receptor mediated IPSPs are key to the modulation of $\gamma$-oscillations. For example, as previously reviewed, agonists and antagonist of $\mathrm{GABA}_{\mathrm{B}}$ receptors have been shown to play a pivotal role in suppression and enhancement of spontaneous or stimulus driven $\gamma$-oscillations, respectively. Moreover, it has been reported that the duration of $\mathrm{GABA}_{\mathrm{A}}$ mediated $\gamma$-oscillations was prolonged through the application of $\mathrm{GABA}_{\mathrm{B}}$ receptor antagonist, 2-OH-saclofen (Whittington et al, 1995), consistent with the finding that $\mathrm{GABA}_{\mathrm{B}}$ mediated IPSPs exert inhibitory control over $\mathrm{GABA}_{\mathrm{A}}$ receptor mediated IPSPs in the cortex (Scanziani, 2000; Sanger et al, 2001; Brown et al, 2007). Although most of the aforementioned lines of evidence were derived from hippocampal recordings in animals, our findings provide human neurophysiological evidence for $\mathrm{GABA}_{B}$ receptor 

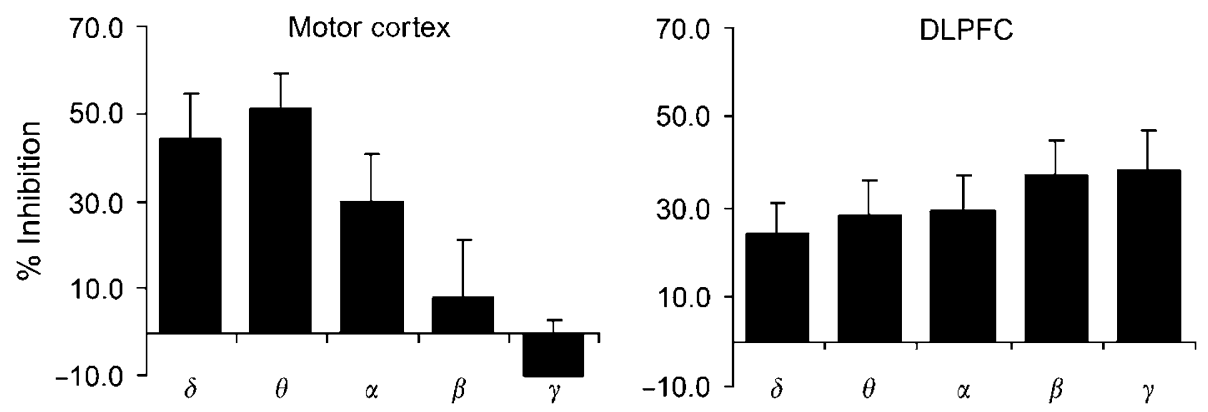

Figure 3 Differential response of cortical oscillations to application of $\mathrm{LICl}$ in the motor cortex and DLPFC. Histograms represent inhibition of cortical oscillations, obtained through equation (I) (see Methods section), in response to activation of $\mathrm{GABA}_{\mathrm{B}}$ mediated inhibitory neurotransmission, induced by $\mathrm{LICl}_{100}$, and averaged across 14 subjects. In the motor cortex (left panel), LICl resulted in significant suppression of $\delta$-, $\theta-$, and $\alpha$-oscillations but $\beta$ - and $\gamma$-oscillations were not inhibited. In the DLPFC (right panel), LICI resulted in significant suppression of all frequency bands.
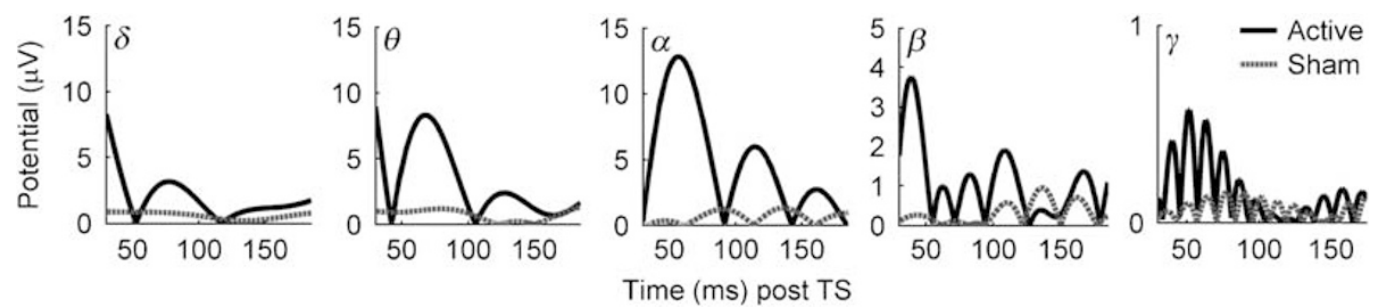

Figure 4 Effect of TMS click-induced auditory activation in the motor cortex. Mean rectified EEG oscillations recorded following the delivery of single pulse of active (solid waveforms) and sham (dash waveforms) stimulation to the left motor cortex of a single subject. In all figures, the $x$-axis represents time after delivery of TS, and the $y$-axis represents evoked potentials recorded from C3 electrode, which lies nearest to the motor cortex.
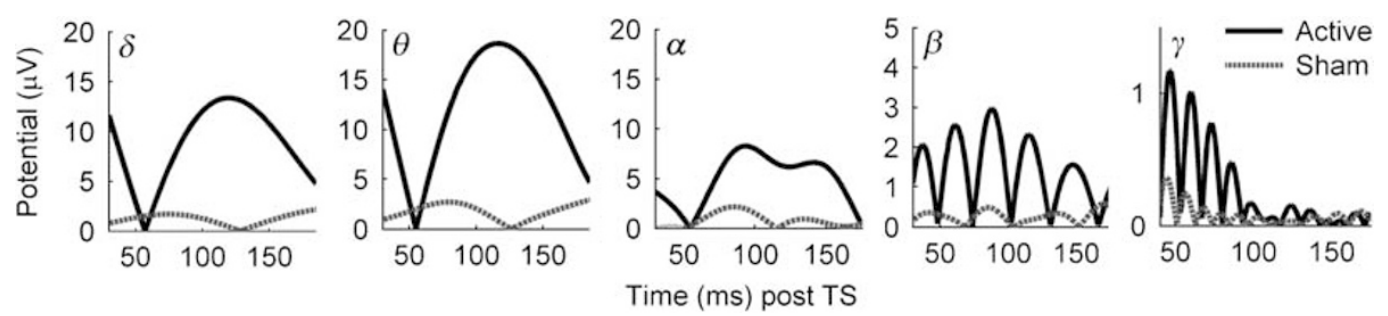

Figure 5 Effect of TMS click-induced auditory activation in the DLPFC. Rectified EEG potentials in each frequency band recorded following the delivery of single pulse of active (solid waveform) and sham (dash waveform) stimulation to the left DLPFC of a single subject. In all figures, the $x$-axis represents time after delivery of TS, and the $y$-axis represents evoked potentials recorded from AF3 electrode, which optimally represents the overlap of BAs 9 and 46 of the DLPFC.

mediated inhibition of $\gamma$-oscillations in the DLPFC but not in the motor cortex. Such specificity is understandable visà-vis the critical role that $\gamma$-oscillations have been proposed to play in the coordination of higher order cognitive functions.

Cortical oscillations in $\gamma$-band frequency represent important neurophysiological processes, which may subserve higher order cognitive functions such as feature binding and working memory (Tallon-Baudry and Bertrand, 1999; Constantinidis et al, 2002; Lewis et al, 2005), whereas the disruption of $\gamma$-oscillations have been reported in neuropsychiatric disorders such as schizophrenia (Spencer et al, 2003; Cho et al, 2006; Light et al, 2006). However, it remains unclear how the inhibition of $\gamma$-oscillations in the DLFPC subserve various cognitive functions. In this regard, several theories have been proposed. First, it has been suggested that the successful encoding of information may depend on its arrival time relative to the $\gamma$-cycle (Fries et al, 2007). For example, information arriving during the fading phase of inhibition would be potentiated, whereas information arriving at the beginning of the inhibitory period will be blocked from further propagation (Fries et al, 2007). Second, recordings from the DLPFC of monkeys engaged in a spatial working memory task demonstrated that the activity of inhibitory neurons were maximal at different time intervals during the task performance, suggesting that inhibitory interneurons shape the time course for the prefrontal pyramidal neuron activation (Constantinidis et al, 2002). That is, pyramidal neurons were maximally active when the fast spiking interneurons were not firing (Wilson et al, 1994), suggesting that the functional role of inhibition may be to shape the temporal profile of incoming information during different phases of cognitive tasks such as working memory. Our finding that inhibition of $\gamma$-oscillations was present in the DLPFC compared to the motor cortex, therefore, may 
suggest that neurocircuitry mediating such inhibition may be an important mechanism responsible for maintaining optimal cognitive performance.

The results of this study are limited in several important ways. First, further pharmacological studies are necessary to investigate the neurophysiological underpinnings of LICIinduced inhibition of $\gamma$-oscillations in the DLPFC. For example, the methods used in this study should be extended to examine the effects of a $\mathrm{GABA}_{\mathrm{B}}$ receptor agonist (ie, baclofen) on LICI-induced inhibition of $\gamma$-oscillations in the DLPFC in healthy human subjects. In addition, these methods can be applied to individuals who suffer from DLPFC impairments (eg, patients with schizophrenia) to investigate the effects of LICI on $\gamma$-oscillations, findings that may further elucidate the neural underpinnings of cognitive impairments in this disorder. Second, the DLPFC was stimulated using an intensity that was determined based on the activation of the motor cortex. Although our previous studies have shown that these intensities are sufficient to activate the DLPFC (Daskalakis et al, 2008), adjusting TMS intensities to more precisely target DLPFC excitability may be preferred particularly as we cannot be absolutely certain that spectral differences observed between these cortical regions (ie, DLPFC $v s$ motor cortex) may not be accounted for by the differences in the excitability of these cortical regions at the same stimulus intensity. Similarly, the coil was held in the same orientation over the DLPFC as over the motor cortex such that in the motor cortex the induced current was perpendicular to the presumed direction of central sulcus. However, this likely did not always result in an induced current that was perpendicular to the prefrontal gyrus. Our results, however, suggest that this orientation over the DLPFC was indeed effective in activating interneurons in the DLPFC (Figure 1). It is recommended, however, that future TMS-EEG studies examine the effect of coil orientation vis-à-vis cortical activation to ensure that such methods are indeed optimal in DLPFC stimulation. Third, although we have suggested that inhibition of TMSinduced EEG is cortical in nature, other sources may also contribute to this inhibitory effect. For example, TMS stimulation of the motor cortex generates hand movement that may be recorded on EEG as sensory evoked potentials. It has been demonstrated that modulation of sensory evoked potentials causes an increase in $\beta$-oscillations in the motor cortex (Lalo et al, 2007). Therefore, in our study, the modulation of sensory afferent stimulation occurring in response to APB activation from single and paired pulse TMS of the motor cortex may have contributed to the potentiation of $\beta$-oscillations and lack of $\mathrm{CI}_{\beta}$ in this region. Furthermore, as sham stimulation does not produce such sensory evoked potentials, subtracting waveforms following sham stimulation from the waveforms generated following active stimulation may not completely control for such effects of TMS on EEG waveforms. Another important limitation of this study is the relatively small sample size. Replicating these findings in a larger subject sample should minimize type II error and stabilize statistical parameter estimates (Norman and Streiner, 2000). Finally, though we have made inferences for the role of inhibition of $\gamma$-oscillations vis-à-vis cognition, there is currently no direct evidence to support these findings. Comparing dimensions of cognitive performance mediated by frontal brain regions with inhibition of $\gamma$-oscillations may help to elucidate further the complex role these processes play in the higher order cognitive processing.

In summary, our findings suggest that LICI results in suppression of $\gamma$-oscillations in DLPFC but not in the motor cortex. Such specificity suggests that the modulation of $\gamma$-oscillations may represent an important neurophysiological process that may, in part, be responsible for optimal DLPFC functioning in healthy human subjects.

\section{ACKNOWLEDGEMENTS}

This work was funded, in part, by the Canadian Institutes of Health Research (CIHR; grant no. MOP 62917 to RC), CIHR Clinician Scientist Award (ZJD), by a National Health and Medical Research Council (NHMRC) Practitioner Fellowship (PBF), and by Constance and Stephen Lieber through a National Alliance for Research on Schizophrenia and Depression Lieber Young Investigator award (ZJD, PBF). ZJD and PBF have both received external funding through Neuronetics Inc. We acknowledge the assistance of all persons and volunteers whose participation was essential in the successful completion of this study.

\section{DISCLOSURE/CONFLICT OF INTEREST}

ZJD has received funding from Neuronetics Ltd as part of participation in a multisite trial, and operational funding from Aspect Medical Systems Inc. RC has received compensation from Allergan, Novartis, Preswick Pharmaceuticals, and research grant from Medtronic Inc.

PBF is funded by a NHMRC Practitioner Fellowship. He has received funding from Neuronetics Ltd as part of participation in a multisite trial. WW, MSB, and FF have no financial interests to disclose.

\section{REFERENCES}

Bartos M, Vida I, Jonas P (2007). Synaptic mechanisms of synchronized gamma oscillations in inhibitory interneuron networks. Nat Rev Neurosci 8: 45-56.

Bracci E, Vreugdenhil M, Hack SP, Jefferys JG (2001). Dynamic modulation of excitation and inhibition during stimulation at gamma and beta frequencies in the CA1 hippocampal region. J Neurophysiol 85: 2412-2422.

Bragin A, Jando G, Nadasdy Z, Hetke J, Wise K, Buzsaki G (1995). Gamma $(40-100 \mathrm{~Hz})$ oscillation in the hippocampus of the behaving rat. $J$ Neurosci 15: 47-60.

Brown JT, Davies CH, Randall AD (2007). Synaptic activation of GABA(B) receptors regulates neuronal network activity and entrainment. Eur J Neurosci 25: 2982-2990.

Chen $\mathrm{R}$ (2004). Interactions between inhibitory and excitatory circuits in the human motor cortex. Exp Brain Res 154: 1-10.

Cho RY, Konecky RO, Carter CS (2006). Impairments in frontal cortical gamma synchrony and cognitive control in schizophrenia. Proc Natl Acad Sci USA 103: 19878-19883.

Chu J, Gunraj C, Chen R (2008). Possible differences between the time courses of presynaptic and postsynaptic GABA(B) mediated inhibition in the human motor cortex. Exp Brain Res 184: 571-577.

Constantinidis C, Williams GV, Goldman-Rakic PS (2002). A role for inhibition in shaping the temporal flow of information in prefrontal cortex. Nat Neurosci 5: 175-180. 
Croft RJ, Chandler JS, Barry RJ, Cooper NR, Clarke AR (2005). EOG correction: a comparison of four methods. Psychophysiology 42: 16-24.

Cui RQ, Huter D, Lang W, Deecke L (1999). Neuroimage of voluntary movement: topography of the Bereitschaftspotential, a 64-channel DC current source density study. Neuroimage 9: $124-134$.

Daskalakis ZJ, Christensen BK, Fitzgerald PB, Roshan L, Chen R (2002). The mechanisms of interhemispheric inhibition in the human motor cortex. J Physiol 543: 317-326.

Daskalakis ZJ, Farzan F, Barr MS, Maller JJ, Chen R, Fitzgerald PB (2008). Long-interval cortical inhibition from the dorsolateral prefrontal cortex: a TMS-EEG study. Neuropsychopharmacology 33: $2860-2869$.

Deisz RA (1999). GABA(B) receptor-mediated effects in human and rat neocortical neurones in vitro. Neuropharmacology 38: 1755-1766.

Delorme A, Makeig S (2004). EEGLAB: an open source toolbox for analysis of single-trial EEG dynamics including independent component analysis. J Neurosci Methods 134: 9-21.

Florian J, Muller-Dahlhaus M, Liu Y, Ziemann U (2008). Inhibitory circuits and the nature of their interactions in the human motor cortex a pharmacological TMS study. J Physiol 586: 495-514.

Fries P, Nikolic D, Singer W (2007). The gamma cycle. Trends Neurosci 30: 309-316.

Glahn DC, Ragland JD, Abramoff A, Barrett J, Laird AR, Bearden CE et al (2005). Beyond hypofrontality: a quantitative metaanalysis of functional neuroimaging studies of working memory in schizophrenia. Hum Brain Mapp 25: 60-69.

Herwig U, Satrapi P, Schonfeldt-Lecuona C (2003). Using the international 10-20 EEG system for positioning of transcranial magnetic stimulation. Brain Topogr 16: 95-99.

Howard MW, Rizzuto DS, Caplan JB, Madsen JR, Lisman J, Aschenbrenner-Scheibe $\mathrm{R}$ et al (2003). Gamma oscillations correlate with working memory load in humans. Cereb Cortex 13: $1369-1374$.

Jefferys JG, Traub RD, Whittington MA (1996). Neuronal networks for induced ' $40 \mathrm{~Hz}$ ' rhythms. Trends Neurosci 19: 202-208.

Kaiser J, Lutzenberger W (2003). Induced gamma-band activity and human brain function. Neuroscientist 9: 475-484.

Kujirai T, Caramia MD, Rothwell JC, Day BL, Thompson PD, Ferbert A et al (1993). Corticocortical inhibition in human motor cortex. J Physiol 471: 501-519.

Lalo E, Gilbertson T, Doyle L, Di Lazzaro V, Cioni B, Brown P (2007). Phasic increases in cortical beta activity are associated with alterations in sensory processing in the human. Exp Brain Res 177: 137-145.

Leung LS, Shen B (2007). GABAB receptor blockade enhances theta and gamma rhythms in the hippocampus of behaving rats. Hippocampus 17: 281-291.

Lewis DA, Hashimoto T, Volk DW (2005). Cortical inhibitory neurons and schizophrenia. Nat Rev Neurosci 6: 312-324.

Light GA, Hsu JL, Hsieh MH, Meyer-Gomes K, Sprock J, Swerdlow NR et al (2006). Gamma band oscillations reveal neural network cortical coherence dysfunction in schizophrenia patients. Biol Psychiatry 60: 1231-1240.

Mann EO, Paulsen O (2007). Role of GABAergic inhibition in hippocampal network oscillations. Trends Neurosci 30: 343-349.

Mann EO, Radcliffe CA, Paulsen O (2005). Hippocampal gammafrequency oscillations: from interneurones to pyramidal cells, and back. J Physiol 562: 55-63.

Marrosu F, Santoni F, Fa M, Puligheddu M, Barberini L, Genugu F et al (2006). Beta and gamma range EEG power-spectrum correlation with spiking discharges in DBA/2J mice absence model: role of GABA receptors. Epilepsia 47: 489-494.
McDonnell MN, Orekhov Y, Ziemann U (2006). The role of $\mathrm{GABA}(\mathrm{B})$ receptors in intracortical inhibition in the human motor cortex. Exp Brain Res 173: 86-93.

Mendrek A, Kiehl KA, Smith AM, Irwin D, Forster BB, Liddle PF (2005). Dysfunction of a distributed neural circuitry in schizophrenia patients during a working-memory performance. Psychol Med 35: 187-196.

Missonnier P, Leonards U, Gold G, Palix J, Ibanez V, Giannakopoulos $P$ (2003). A new electrophysiological index for working memory load in humans. Neuroreport 14: 1451-1455.

Morey L (1991). Personality Assessment Inventory Professional Manual. Psychological Assessment Resources: Odessa, FL.

Morey L (1996). An Interpretative Guide to the Personality Assessment Inventory (PAI). Psychological Assessment Resources: Odessa, FL.

Nakamura H, Kitagawa H, Kawaguchi Y, Tsuji H (1997). Intracortical facilitation and inhibition after transcranial magnetic stimulation in conscious humans. J Physiol 498(Part 3): 817-823.

Norman GR, Streiner DL (2000). Biostatistics - The Bare Essentials. BC Decker Inc.: Hamilton.

Oldfield RC (1971). The assessment and analysis of handedness: the Edinburgh inventory. Neuropsychologia 9: 97-113.

Pfurtscheller G, Stancak Jr A, Edlinger G (1997). On the existence of different types of central beta rhythms below $30 \mathrm{~Hz}$. Electroencephalogr Clin Neurophysiol 102: 316-325.

Sanger TD, Garg RR, Chen R (2001). Interactions between two different inhibitory systems in the human motor cortex. J Physiol 530: 307-317.

Scanziani M (2000). GABA spillover activates postsynaptic GABA(B) receptors to control rhythmic hippocampal activity. Neuron 25: 673-681.

Spencer KM, Nestor PG, Niznikiewicz MA, Salisbury DF, Shenton ME, McCarley RW (2003). Abnormal neural synchrony in schizophrenia. J Neurosci 23: 7407-7411.

Tallon-Baudry C, Bertrand O (1999). Oscillatory gamma activity in humans and its role in object representation. Trends Cogn Sci 3: 151-162.

Tan HY, Choo WC, Fones CS, Chee MW (2005). fMRI study of maintenance and manipulation processes within working memory in first-episode schizophrenia. Am J Psychiatry 162: 1849-1858.

Traub RD, Jefferys JG, Whittington MA (1997). Simulation of gamma rhythms in networks of interneurons and pyramidal cells. J Comput Neurosci 4: 141-150.

Traub RD, Spruston N, Soltesz I, Konnerth A, Whittington MA, Jefferys GR (1998). Gamma-frequency oscillations: a neuronal population phenomenon, regulated by synaptic and intrinsic cellular processes, and inducing synaptic plasticity. Prog Neurobiol 55: 563-575.

Traub RD, Whittington MA, Colling SB, Buzsaki G, Jefferys JG (1996). Analysis of gamma rhythms in the rat hippocampus in vitro and in vivo. J Physiol 493(Part 2): 471-484.

Trevino M, Vivar C, Gutierrez R (2007). Beta/gamma oscillatory activity in the CA3 hippocampal area is depressed by aberrant GABAergic transmission from the dentate gyrus after seizures. J Neurosci 27: 251-259.

Valls-Sole J, Pascual-Leone A, Wassermann EM, Hallett M (1992). Human motor evoked responses to paired transcranial magnetic stimuli. Electroencephalogr Clin Neurophysiol 85: 355-364.

Wang XJ, Buzsaki G (1996). Gamma oscillation by synaptic inhibition in a hippocampal interneuronal network model. J Neurosci 16: 6402-6413.

Werhahn KJ, Kunesch E, Noachtar S, Benecke R, Classen J (1999). Differential effects on motorcortical inhibition induced by blockade of GABA uptake in humans. J Physiol 517(Part 2): 591-597. 
Whittington MA, Traub RD, Jefferys JG (1995). Synchronized oscillations in interneuron networks driven by metabotropic glutamate receptor activation. Nature 373: 612-615.

Whittington MA, Traub RD, Kopell N, Ermentrout B, Buhl EH (2000). Inhibition-based rhythms: experimental and mathematical observations on network dynamics. Int J Psychophysiol 38: 315-336.

Wilson FA, O'Scalaidhe SP, Goldman-Rakic PS (1994). Functional synergism between putative gamma-aminobutyrate-containing neurons and pyramidal neurons in prefrontal cortex. Proc Natl Acad Sci USA 91: 4009-4013.

Ziemann U, Lonnecker S, Steinhoff BJ, Paulus W (1996a). The effect of lorazepam on the motor cortical excitability in man. Exp Brain Res 109: 127-135.

Ziemann U, Rothwell JC, Ridding MC (1996b). Interaction between intracortical inhibition and facilitation in human motor cortex. J Physiol 496(Part 3): 873-881. 